\title{
O conceito de desenvolvimento sustentável: ressignificação pela lógica de acumulação de capital e suas práticas
}

Le Concept de développement durable: resignification de la logique de l'accumulation du capital et de ses pratiques

El concepto de desarrollo sostenible: ressignificación por la lógica de acumulación de capital y sus prácticas

The concept of sustainable development: significance by the logic of capital accumulation and its practices

\section{Letícia Mello de Mendonça}

\section{OpenEdition}

Journals

\section{Edição electrónica}

URL: http://journals.openedition.org/espacoeconomia/7674

DOI: $10.4000 /$ espacoeconomia.7674

ISSN: 2317-7837

\section{Editora}

Núcleo de Pesquisa Espaço \& Economia

\section{Refêrencia eletrónica}

Letícia Mello de Mendonça, « O conceito de desenvolvimento sustentável: ressignificação pela lógica de acumulação de capital e suas práticas », Espaço e Economia [Online], 15 | 2019, posto online no dia 30 outubro 2019, consultado o 05 novembro 2019. URL : http://journals.openedition.org/ espacoeconomia/7674; DOI : ERREUR PDO dans /localdata/www-bin/Core/Core/Db/Db.class.php L. 34 : SQLSTATE[HY000] [1040] Too many connections

Este documento foi criado de forma automática no dia 5 novembro 2019.

(c) NUPEE 


\title{
O conceito de desenvolvimento sustentável: ressignificação pela lógica de acumulação de capital e suas práticas
}

\author{
Le Concept de développement durable: resignification de la logique de \\ l'accumulation du capital et de ses pratiques \\ El concepto de desarrollo sostenible: ressignificación por la lógica de \\ acumulación de capital y sus prácticas \\ The concept of sustainable development: significance by the logic of capital \\ accumulation and its practices
}

Letícia Mello de Mendonça

\section{INTRODUÇÃO}

1 A discussão ambiental tem se tornado, desde meados do século XX, uma questão-chave das relações internacionais, inspirando grandes conferências mundiais exclusivamente sobre o tema. A melhoria da gestão dos recursos naturais e a conservação do meio ambiente de maneira geral se tornaram preocupações emergenciais dos principais organismos internacionais, dedicando acordos multilaterais, relatórios temáticos específicos e megaencontros diplomáticos com intensa participação da imprensa internacional.

o desenvolvimento produtivo industrial se tornou o maior responsável pelas degradações ambientais no final do milênio. $O$ avanço do aquecimento global, do desmatamento e da poluição em diversos âmbitos chegaram a níveis extremos que afetam as gerações atuais e futuras. As práticas produtivas para o crescimento econômico atingiram um ponto crítico no uso desenfreado da natureza enquanto recurso, tornando urgente o rearranjo destas práticas para o equilíbrio com o meio 
ambiente, de forma a não prejudicar seu uso como recurso natural e como ecossistema responsável pela vida do planeta. As atuais tendências econômicas globais demonstram a necessidade de repensar o uso do meio ambiente, buscando equilibrar a preservação ambiental sem o comprometimento do crescimento econômico. Tal ideia é refletida no conceito de desenvolvimento sustentável.

3 Este trabalho visa descrever a trajetória das discussões sobre a questão ambiental no cenário internacional, com foco nas principais conferências ambientais internacionais realizada pela Organização das Nações Unidas desde o início da década de 70 . Em seguida, explica-se a apropriação do uso da natureza pela lógica de acumulação de capital por meio da produção em grande escala, atual configuração do sistema econômico mundial, e como se dá a busca pelo equilíbrio entre economia-ecologia e lucro produtivo-gestão dos recursos naturais. Por fim, faz-se uma comparação entre os projetos de "Cidade Sustentável" de Seropédica (Brasil) e a eco-town de Kitakyushu (Japão), a fim de demonstrar como funcionam os discursos e as dinâmicas acerca do desenvolvimento sustentável na execução prática do conceito.

\section{AS DISCUSSÕES E CONFERÊNCIAS INTERNACIONAIS}

4 O aumento da preocupação com a proteção ambiental de forma mais veemente data da Segunda Guerra Mundial, onde foi atestada o tamanho da capacidade de destruição alcançada pelo homem com as bombas nucleares de Hiroshima e Nagasaki, no Japão. $O$ episódio se caracteriza não apenas pela destruição iminente do meio ambiente e da vida humana, mas por suas consequências para as gerações futuras, como doenças crônicas, infertilidade do solo e contaminação da água, por exemplo. Paralela à criação da Organização das Nações Unidas em 1945 para evitar a repetição de conflitos mundiais e garantir a manutenção da paz, surgem discussões internacionais acerca da intenção de conter a degradação ambiental em grandes níveis já constatada desde o fim da guerra.

5 As décadas seguintes levantaram preocupações similares, como a utilização excessiva de agrotóxicos ${ }^{1}$ nas plantações de grande escala na década de 60 nos Estados Unidos que causaram danos também geracionais para o solo e para a população, assim como as crises de fornecimento de petróleo na década de 70 que identificaram a dependência sistêmica de recursos naturais não-renováveis, o que poderia levar ao colapso econômico de diversos países.

6 Entre o fim dos anos 60 e início dos anos 70, é elaborado o Relatório Meadows², habitualmente conhecido como "Limites do Crescimento", que relacionava o desenvolvimento econômico e o crescimento progressivo da população mundial à utilização desenfreada de recursos naturais necessários para a manutenção da vida. 0 momento de incertezas sobre a durabilidade dos recursos e a necessidade de proteção ambiental atrelados ao tom pessimista das ações humanas sobre os avanços do desenvolvimento industrial deram suporte à criação de um encontro mundial realizado pela ONU, a Conferência das Nações Unidas sobre Meio Ambiente Humano, sediado na cidade de Estocolmo (Suécia) em 1972. Dentre as propostas tratadas na conferência, destacam-se o combate à poluição e a criação do PNUMA (Programa das Nações Unidas para o Meio Ambiente) como agência específica das ações para preservação ambiental.

7 A realização da Conferência no auge da disputa ideológica da Guerra Fria ${ }^{3}$ também desencadeou um embate entre os países participantes, caracterizado pela disputa entre o desenvolvimentismo dos países centrais e o conceito de "crescimento zero" apoiado 
pelos países periféricos - que visava congelar o desenvolvimento produtivo e econômico dos países industrializados sob a justificativa de conter o uso indiscriminado de recursos ambientais.

8 Em meados da década de 80, um novo documento chamado Relatório Brundtland ${ }^{4}$, conhecido como "Nosso Futuro Comum", foi elaborado em parceria com a ONU. O relatório apresentava uma tônica oposta ao anterior, com uma visão mais colaborativa e otimista acerca das possibilidades de cooperação e construção de um futuro mais igualitário ecológica e humanamente. Todavia, as conclusões propostas se mostraram vagas, como a conceitualização do termo "desenvolvimento sustentável" sem características mais definidas, e discussões pautadas na minimização da gravidade dos problemas ambientais e em pequenas soluções interdisciplinares para práticas limpas, mas sem prejuízo do desenvolvimento.

O próximo encontro aconteceu somente 20 anos depois, seguindo a argumentação proposta pelo novo relatório, dado o dilema acerca do crescimento econômico da Conferência de Estocolmo. Concomitantemente com o término da Guerra Fria e o desmantelamento da União Soviética, o modelo capitalista na década de 90 se tornara o cerne do sistema econômico mundial, acompanhado da disseminação do neoliberalismo, modelo que segue a reforma da doutrina liberal clássica, adaptando o conceito de não-intervenção do Estado na economia para algumas das necessidades dos Estados assistencialistas. Dessa forma, toda a discussão internacional sobre a questão ambiental precisava ser ressignificada às necessidades da época. A Conferência das Nações Unidas sobre Meio Ambiente e Desenvolvimento (1992) dessa vez fora sediada no Brasil, um país emergente, à perspectiva festiva da Cidade Maravilhosa ${ }^{5}$. 0 foco da conferência - popularizada como ECO-92 - foi guiado pela biodiversidade característica do país e a gestão dos recursos naturais alimentada pelo argumento desenvolvimentista. A fisionomia do conceito de "desenvolvimento sustentável" começa a ser construída em um megaevento mundial.

Em 2002, o conceito aparece explicitamente na Cúpula Mundial sobre Desenvolvimento Sustentável, ocorrida em Joanesburgo (África do Sul) para avaliar o progresso alcançado pelos acordos estabelecidos na ECO-92. Apesar de organizada também pela ONU, não se tratava de uma conferência oficial como as anteriores. A inovação trazida neste encontro foi a inclusão de pautas sociais, como erradicação da fome e da pobreza, incluídas nas discussões anteriores como preocupações implícitas e secundárias. 0 encontro ficou conhecido como RIO+10, pela proximidade da conferência seguinte, a RIO+20.

11 Consolidadas as determinações produtivas e econômicas do modelo capitalista como fundamentos da nova ordem mundial, é realizada uma nova reunião oficial para estabelecer os preceitos inicialmente formulados na anterior. A Conferência das Nações Unidas sobre Desenvolvimento Sustentável - a RIO+20 - é sediada novamente no Rio de Janeiro (Brasil) em 2012. Esta assembleia carrega o legado misto das conferências anteriores: uma desconfiança de megaeventos diplomáticos, o questionamento da consistência científica dos impactos ambientais e climáticos e a proposição de soluções práticas generalizadas e demasiado redundantes.

O grande resultado da conferência se encontra na formulação e definição de conceitos, com a caracterização oficial do conceito de "desenvolvimento sustentável" e a aparição de outros como "economia verde"', que dão sustentação à ideia de que a ressignificação 
dos conceitos e práticas ecológicos dependem, indubitavelmente, das necessidades econômicas e produtivas do sistema capitalista internacional.

\section{A APROPRIAÇÃO DA NATUREZA COMO RECURSO}

13 A globalização se apresenta como um processo contínuo e irreversível instituído pelo avanço do sistema capitalista mundial (BAUMAN, 1999). É um processo atrelado em sua essência às mudanças econômicas, e estas exprimem as novas relações do capital, tanto quanto suas consequências para adaptação dessas relações, como reestruturação econômica, política, social, espacial e ambiental.

Nas Conferências das Partes das Nações Unidas voltadas ao tema do meio ambiente, é possível perceber a evolução da discussão acerca da problemática ambiental, cada vez mais envolta pelo sistema capitalista e atrelada ao desenvolvimento econômico dos países (CORRÊA DO LAGO, 2013). o dissenso entre as partes na Conferência de Estocolmo sobre os limites do desenvolvimentismo, bem como a reiteração da necessidade de controle das atividades que contribuem para a degradação ambiental evidenciadas na ECO-92 e na RIO+20 - caracterizadas pelo conceito de desenvolvimento sustentável evidenciam a teoria de Immanuel Wallerstein sobre a desestruturação do sistema econômico capitalista atual. Para o autor, o esgotamento ecológico é uma tendência da ruptura já em curso do modelo, caracterizada pela disputa entre o lucro da produção de grandes empresas e a preservação dos recursos naturais utilizadas de forma inescrupulosa pelas mesmas (WALLERSTEIN, 2003). Desse modo, não é possível preservar o exercício de acumulação de capital pela produção em larga escala sem limitar o uso dos recursos naturais.

15 A ECO-92 e a RIO+10, ainda que opostas às disposições de crescimento zero da Conferência de Estocolmo, podem ser consideradas como parte da transição entre as perspectivas econômicas que transcrevem as conferências ambientais internacionais. Durante a ECO-92, o sistema capitalista experimentava as consequências do neoliberalismo, modelo político-econômico que David Harvey apontou como contraditório por defender concepção liberal clássica de não-intervenção do Estado na economia e, ainda assim, permitir a formação de monopólios privados de mercado sobre os recursos ambientais, que deveriam ser considerados bens comuns da população mundial. Há também a contradição entre o bem-estar social proposto como um dos princípios da teoria capitalista e o tratamento do meio ambiente como mercadoria diante da política do livre-mercado (HARVEY, 2008). Nesse mesmo sentido, Zigmunt Bauman também define de maneira direta as consequências da relação hierárquica entre economia e ecologia, ao dizer que “(...) o poder desarraigado (...) é livre para explorar e abandonar as consequências dessa exploração" (BAUMAN, 1999, p. 16).

16 O avanço da globalização e do sistema capitalista caminha para a reestruturação espacial das cidades como reflexo da exploração de novas áreas por empresas onde os centros de decisão se mantêm em grandes aglomerações urbanas e a área produtiva migra para regiões onde há incentivo e chances de maiores lucros (LENCIONI, 2015). Dessa forma, o lucro se sobrepõe aos danos ambientais ocasionados pelas mudanças de região das empresas, que fisicamente se direcionam às áreas com custos de produção reduzidos, como mão-de-obra barata, abundância de matéria-prima, redução do transporte, entre outros - geralmente áreas rurais - enquanto seus centros de decisão 
se instalam em aglomerados urbanos economicamente relevantes no sistema internacional (BAUMAN, 1999). Milton Santos explica esta dinâmica de reorganização do espaço tanto da perspectiva regional, com mudanças locais de fábricas, como da perspectiva global, com a migração de multinacionais para países periféricos e a manutenção dos centros de decisões em países centrais (SANTOS, 2000).

Com a preocupação central do sistema sendo o acúmulo de capital, as empresas buscam externalizar os custos da sua produção para aumentar seus lucros, utilizando de forma inescrupulosa os recursos ambientais disponíveis e evitando o pagamento de impostos ao Estado pela exploração (WALLERSTEIN, 1999). A reorganização do espaço antes rural para alocação de indústrias caracteriza um exemplo destas práticas de externalização de custos (HARVEY, 2008) e mobilidade do capital e da produção (BAUMAN, 1999) particulares do modelo capitalista, no qual só há espaço para a natureza enquanto mercadoria e recurso produtivo. Os recursos naturais são utilizados como matériaprima e o meio ambiente como espaço de organização da produção, sem que haja preocupação ou ressarcimento aos danos ecológicos causados pela instalação de grandes fábricas, assim como benefícios à população local em forma de incentivos sociais, atendendo apenas ao resultado de lucro das grandes empresas.

18 A construção da perspectiva de conservação ambiental, ultimada pela construção do conceito de desenvolvimento sustentável, evidencia a apropriação do sentido da sustentabilidade ecológica pela expectativa de lucro e crescimento econômico e industrial (OLIVEIRA, 2012).

\section{AS PRÁTICAS PRODUTIVAS-AMBIENTAIS DO DESENVOLVIMENTO SUSTENTÁVEL}

19 A implementação de projetos governamentais para difundir práticas sustentáveis tem se tornado uma realidade comum ao redor do mundo. Tanto governos nacionais e locais como organismos internacionais desenvolvem projetos de lei ou programas de aceleração para o desenvolvimento sustentável em diversos âmbitos. Os projetos de Seropédica e Kitakyushư foram designados para ilustrar alguns desses programas implantados em diferentes áreas do globo e sob diferentes perspectivas: como discursos de governança e soluções viáveis aplicadas.

Esse processo é definido pelo conceito de reestruturação produtiva do espaço (OLIVEIRA, 2016) que explica a sua reconfiguração pelas novas dinâmicas de produção e acumulação de capital. Nesse sentido, observa-se a reconstrução de cidades para atender às demandas capitalistas de escoamento da mercadoria, de alocação de indústrias e de utilização da natureza como recurso. Desse modo, define-se um novo modelo produtivo de gestão para a cidade, incluindo a sustentabilidade como uma das forças motriz da sua reconfiguração, sensível à proposta de alinhamento entre a produção em larga escala e a preservação ambiental evidenciada pelo conceito de desenvolvimento sustentável.

\section{O CASO DE SEROPÉDICA}

21 A cidade de Seropédica, localizada na borda metropolitana da cidade do Rio de Janeiro e pertencente à região da Baixada Fluminense, recebeu nos últimos anos a instalação de 
grandes indústrias multinacionais e complexos logísticos, se tornando um exemplo da utilização do conceito de desenvolvimento sustentável enquanto discurso popular atualmente.

Em 2014, a prefeitura adotou o título "Cidade Sustentável” para a implementação de um projeto de reestruturação territorial-produtiva da cidade. Novas empresas - dentre estas complexos logísticos e fábricas multinacionais - seriam alocadas na antiga região rural da cidade, já tida como posição estratégica de escoamento da produção dada a proximidade do Arco Metropolitano ${ }^{8}$, uma das principais vias do estado do Rio de Janeiro. 0 auxílio de subsídios do governo dados às empresas seria revertido em geração de empregos e aumento do bem-estar da população local. As práticas sustentáveis adotadas incluíam, por exemplo, a instalação de diversos pontos de coleta seletiva para reciclagem do lixo, e a proteção ambiental da Floresta Nacional Mário Xavier, localizada na cidade.

Figura 1: logo da Prefeitura de Seropédica após a implementação do projeto "Cidade Sustentável" em 2014.

\section{\$) Seropêdica}

Disponível em: http://seropedica.rj.gov.br/wp-content/uploads/2016/04/logo_site_prefeitura.fw_.png Acesso em 30 de abril de 2019.

Todavia, com a mudança do governo local após as eleições em 2016, o projeto foi encerrado pela nova gestão e o novo título de "Governo do Povo" foi adotado pela prefeitura.

Cerca de 17 empresas foram instaladas desde 2010 na cidade, como a Procter \& Gamble, a Petrobras e o complexo logístico Golgi ${ }^{9}$. Porém a realização do projeto sustentável prometido à população, incluindo os efeitos positivos como melhorias sociais e atividades de preservação ambiental local, foram abandonados. Não há registros públicos de atividades realizadas que sejam relacionadas às propostas do projeto, bem como dados e políticas públicas que comprovem a melhoria da qualidade de vida da população em vista da chegada das empresas.

Figura 2: logo da Prefeitura de Seropédica após a mudança de gestão da cidade nas eleições de 2016 para o título de "Governo do Povo".

\section{(3)}

Disponivel em: http://seropedica.rj.gov.br/wp-content/uploads/2017/06/ topo_pagina_pms-1024x163.png. Acesso em 30 de abril de 2019.

O programa do governo "Cidade Sustentável" de Seropédica demonstra como o discurso do desenvolvimento sustentável é bem recebido pela sociedade atualmente - ainda que não tenha resultados efetivos. A utilização da sustentabilidade enquanto discurso é 
importante para a angariação de votos, ainda que as promessas não sejam cumpridas. No caso específico da cidade, a mudança de gestão comprometeu a viabilidade do projeto "Cidade Sustentável", característica da descontinuidade de políticas públicas em razão da forma como se aplica a governabilidade no Brasil, e como a questão ambiental é posta em segundo plano pela governança.

\section{O CASO DE KITAKYUSHU}

26 A cidade de Kitakyushu, localizada na ilha de Kyushu ao sul do Japão, abriga um complexo metalúrgico de grande porte desde a década de 60. Por conta da grande produção, a região sofre com grave poluição do ar e dos rios, afetando seu ecossistema e a qualidade de vida da população local.

Figura 3: a poluição dos rios da cidade de Kitakyushu na década de 60.

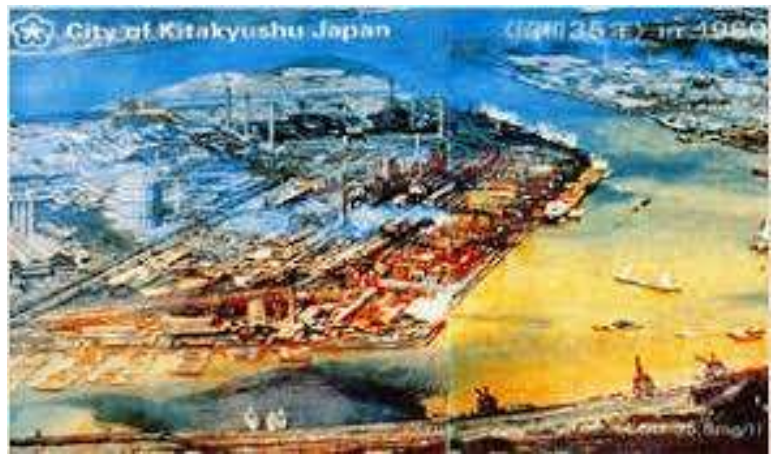

Disponível em: https://www.sbmc.or.jp/english/20041018/Kitakyushu_City_vol2_vol3.htm. Acesso em 30 de abril de 2019.

Figura 4: a poluição do ar pelas fábricas da cidade de Kitakyushu na década de 60.

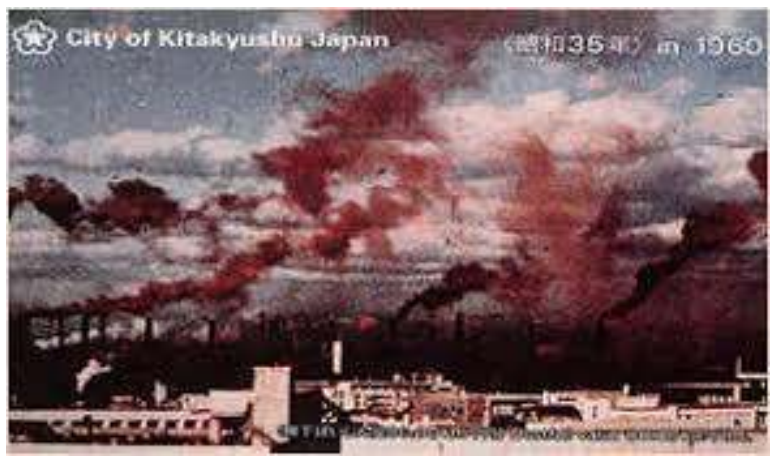

Disponível em: https://www.jica.go.jp/brazil/portuguese/office/news/2013/c8h0vm00004nzhen-att/ c8h0vm00004nzhk0.pdf. Acesso em 30 de abril de 2019.

Desde o fim da década de 80, o governo do Japão instituiu, em um sistema tripé que incluía a parceria de entidades públicas e privadas (locais, nacionais e internacionais) juntamente com a sociedade civil, o projeto KITA (Kitakyushu International TechnoCooperative Association) para a cidade. 0 planejamento incluía a reestruturação industrial e ecológica da cidade, a fim de manter os níveis da produção em larga escala ao tempo que buscava reverter os quadros de poluição e definir novas atividades produtivas e comerciais sustentáveis. 
Figura 5: recuperação dos rios após a implementação do projeto de eco-town na década de 80 .

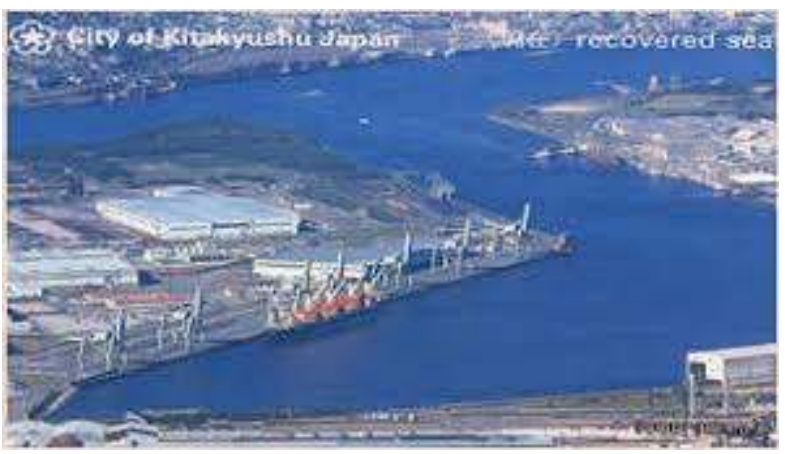

Disponível em: https://www.sbmc.or.jp/english/20041018/Kitakyushu_City_vol2_vol3.htm. Acesso em 30 de abril de 2019.

Figura 6: reversão da poluição do ar após a implementação do projeto de eco-town na década de 80.

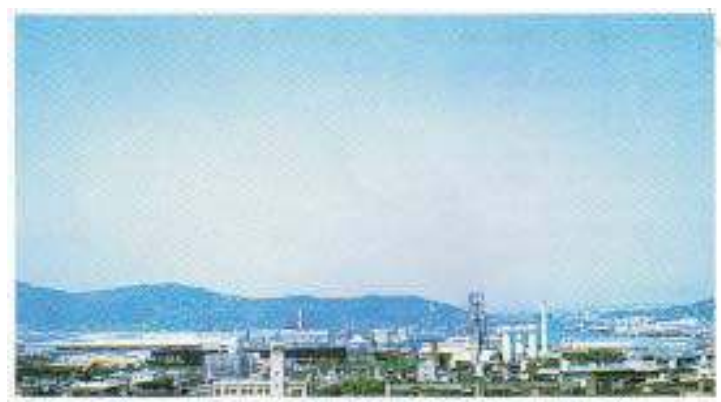

Disponível em: https://www.jica.go.jp/brazil/portuguese/office/news/2013/c8h0vm00004nzhen-att/ c8h0vm00004nzhk0.pdf. Acesso em 30 de abril de 2019.

O projeto foi bem-sucedido em seus objetivos, como reportado por um relatório do Banco Mundial em 1993, e contou com iniciativas como políticas de gênero e produção científica e tecnológica, por exemplo. O sucesso do projeto incluiu a sua internacionalização, de forma que, atualmente, é também exportado para outras regiões do mundo, principalmente países emergentes da Ásia no sul global, como a China. As empresas locais comercializam produtos e serviços sustentáveis, a população redefiniu atividades sociais comuns para o modelo eco-friendly ${ }^{10}$ e o governo implantou projetos e leis de preservação ambiental na região e no país.

Os resultados do projeto incluem redução significativa da emissão de gases poluentes, reciclagem dos resíduos da produção, reutilização de água pelas indústrias e pela população local, produção de energia limpa, modelo de cidade autossustentável, exportação do modelo de planejamento urbano, investimentos em pesquisa e tecnologia, produção e exportação de produtos e serviços sustentáveis.

o projeto de Kitakyushu recebeu premiações nacionais e internacionais, incluindo o prêmio de Primeira Cidade-Modelo para Crescimento Verde da Organização para Cooperação Econômica e Desenvolvimento (OECD), em 2011 ${ }^{11}$.

O protótipo da chamada eco-town ${ }^{12}$ reflete a possibilidade de aplicação do conceito de desenvolvimento sustentável, em que a relação economia-ecologia abrange um tom mais homogêneo. É possível observar um projeto mais devidamente estruturado, e que 
reflete a possibilidade de uma reestruturação produtiva-ambiental para o desenvolvimento sustentável.

\section{CONCLUSÃO}

Os projetos sustentáveis demonstram a aplicação prática - ou o uso apenas como discurso eleitoral - do conceito de desenvolvimento sustentável definido ao longo do tempo. O termo se apresenta como crucial nas discussões internacionais, e com necessidade de execução prática iminente, a fim de garantir a viabilidade do uso de recursos naturais para a conservação ambiental e manutenção da vida das gerações atuais e futuras.

É importante ressaltar o papel histórico da Divisão Internacional do Trabalho na economia internacional abordada por Milton Santos para o entendimento das atividades econômicas produtivas dos países em questão (Japão e Brasil). Após a Segunda Guerra Mundial, o Japão se consolidou como um país central pelo seu alto desenvolvimento tecnológico, enquanto o Brasil ainda estava iniciando seu processo de industrialização. A análise comparativa dos projetos sustentáveis deve levar em conta a capacidade econômica e produtiva dos países em relação aos avanços tecnológicos, recursos disponíveis e capital para investimento no setor produtivo, que são desequilibrados entre os dois países.

Por outro lado, a adequação - de forma geral - dos métodos produtivos à proteção do meio ambiente, todavia, tem se mostrado generalista em todo o mundo. Apesar do aumento da atenção para o tema e da realização de programas por organismos internacionais e projetos governamentais locais, as práticas para o desenvolvimento sustentável não se adequam à realidade e dimensão do problema atualmente. Tais práticas, de modo geral, ainda sobrepõem o lucro e o desenvolvimento econômico acima da conservação de rios, florestas e animais selvagens como bens comuns de toda a humanidade, não-passíveis de exploração pelo capital. A eco-town de Kitakyushu apresentou resultados mais próximos de uma sustentabilidade efetiva no sistema produtivo e de planejamento urbano, enquanto o projeto "Cidade Sustentável" de Seropédica não dispõe de registros de políticas públicas realizadas para este fim.

Enquanto não houver cooperação total entre entidades públicas, privadas e a sociedade civil com medidas efetivas de manutenção da vida ambiental, com ações locais, regionais, nacionais e internacionais que alimentem o progresso da sustentabilidade ambiental acima dos ganhos econômicos - com práticas alternativas de produção como a agroecologia, por exemplo - o planeta seguirá no curso de deterioração dos ecossistemas, da vida ambiental, animal e, sobretudo, humana. 


\section{BIBLIOGRAFIA}

Documentos coletados pelo Prof. Dr. Leandro Dias de Oliveira nos stands da Rio+20 sobre a conferência. 2012.

Documentos coletados pelo Prof. Dr. Leandro Dias de Oliveira nos stands do governo do Japão e da cidade de Kitakyushu na Rio +20. 2012.

ALTVATER, Elmar. O fim do capitalismo como o conhecemos. Rio de Janeiro: Civilização Brasileira, 2010.

BAUMAN, Zigmunt. Tempo e Classe; Guerras espaciais: informe de carreira. In: Globalização: As Consequências Humanas. Rio de Janeiro, 1999.

CORRÊA DO LAGO, André Aranha. Conferências do Desenvolvimento Sustentável. Brasília: FUNAG, 2013.

CORRÊA DO LAGO, André Aranha. Estocolmo, Rio, Joanesburgo: O Brasil e as Três Conferências Ambientais das Nações Unidas. Brasília: FUNAG, 2006.

Declaração da Conferência da ONU no Ambiente Humano. Ministério do Meio Ambiente, 1972. Declaração do Rio sobre Meio Ambiente e Desenvolvimento. Ministério do Meio Ambiente, 1992. HARVEY, David. O Neoliberalismo - Histórias e Implicações. Capítulo 3. São Paulo, 2008. Condição Pós-Moderna. São Paulo, 1992. Justice, Nature and the Geography of Difference. Oxford: Blackwell, 1996.

IMANAGA, Hirosh. Kitakyushu Eco-Town Project: aim at the Sustainable society. Environmental Research Quarterly: 2005.

Kitakyushu Eco-Town Project. The City of Kitakyushu, 2004.

KITAKYUSHU ECO-TOWN PROJECT. The City of Kitakyushu, 2004.

Kitakyushu - City Renaissance Plan's Evaluation Report. 2003.

LENCIONI, Sandra. Urbanização difusa e a constituição de megarregiões - O caso de São Paulo-Rio de Janeiro. 2015.

MEADOWS, Donella H. Limites do crescimento: um relatório para o Projeto do Clube de Roma sobre o dilema da humanidade. São Paulo: Perspectiva, 1973.

Nosso Futuro Comum. Comissão Mundial Sobre Meio Ambiente e Desenvolvimento. Rio de Janeiro: Editora FGV, 1991.

O Futuro que Queremos: Declaração Final da Conferência das Nações Unidas sobre Desenvolvimento Sustentável. Ministério do Meio Ambiente, 2012.

OLIVEIRA, Leandro Dias. “Seropédica Sustentável”: Transformações Ecológico-EconômicoEspaciais Recentes Em Um Lacônico Julgamento. Recôncavo: Revista de História da UNIABEU, 2016.

. A Construção do Desenvolvimento Sustentável na Cidade de Volta Redonda. Mestrado em Geografia. Rio de Janeiro: UERJ, 2006.

A geopolítica do desenvolvimento sustentável: reflexões sobre o encontro entre economia e ecologia. Carta Internacional (ABRI), 2012. 
Rio+20: Reflexões sobre Geopolítica e Ideologia. Ano II, número 4. Rio de Janeiro: Espaço e Economia: Revista Brasileira de Geografia Econômica, 2014.

; ROCHA, André Santos da. As Novas Dinâmicas Produtivas em curso na Baixada Fluminense. In: Revista Pilares da História. Duque de Caxias, 2012.

Projeto de Lei: Plano Diretor do Município de Seropédica. Departamento de Imprensa da Prefeitura de Seropédica, 2006.

SANTOS, Milton. Por uma Outra Globalização. Rio de Janeiro: Editora Record, 2000.

A Natureza do Espaço: Técnica e Tempo, Razão e Emoção. São Paulo: EDUSP, 2014.

Metamorfoses do Espaço Habitado: Fundamentos Teóricos e Metodológicos da

Geografia. São Paulo: EDUSP, 2014.

STORPER, Michael; VENABLES, Anthony. O Burburinho: a força econômica da cidade. In: CAMPOLINA DINIZ, Clélio; LEMOS, Mauro Borges (Orgs.). Economia e Território. Belo Horizonte: Editora da UFMG, 2005.

WALLERSTEIN, Immanuel. “Mundialização ou Era de Transição? Uma Visão de Longo Prazo da Trajetória do Sistema-Mundo”. In: Uma Nova Fase do Capitalismo? São Paulo: Xamã, 2003.

\section{NOTAS}

1. O livro Primavera Silenciosa (1962), da ambientalista Rachel Carson, descreve as preocupações acerca do aumento deliberado do uso de agrotóxicos e seus efeitos sobre a vida humana e ambiental, se tornando um marco da literatura relacionada ao meio ambiente.

2. $O$ relatório Meadows (Limites do Crescimento) é um documento publicado em 1972, elaborado por pesquisadores do MIT (Massachusetts Institute of Technology, EUA) e financiado pelo Clube de Roma (grupo de intelectuais relacionados à política e economia internacional), chefiado pela cientista ambiental Dana Meadows.

3. Disputa ideológica entre países capitalistas e socialistas no mundo bipolar. A guerra data do fim da Segunda Guerra Mundial até o desmantelamento do maior país socialista, a União das Repúblicas Soviéticas Socialistas (URSS), no início da década de 90.

4. O Relatório Brundtland (Nosso Futuro Comum) foi publicado em 1987 pela Comissão Mundial sobre o Meio Ambiente e Desenvolvimento liderada pela primeira ministra norueguesa Gro Brundtland.

5. Homônimo da cidade do Rio de Janeiro.

6. A economia verde é um conjunto de processos produtivos, de comércio e de serviços que atuam na promoção do desenvolvimento sustentável, recuperando essencialmente seu caráter econômico.

7. Os projetos escolhidos para exemplificar as práticas produtivas-ambientais do desenvolvimento sustentável foram baseados na pesquisa de iniciação científica realizada pela autora deste artigo, sob orientação do Prof. Dr. Leandro Dias de Oliveira, que trata da reestruturação produtiva-territorial da cidade de Seropédica e faz uma análise comparativa entre esta e o projeto de eco-town de Kitakyushu. A pesquisa foi financiada pelo CNPq no biênio 2016-2018.

8. O Arco Metropolitano é o nome popular da Rodovia Raphael de Almeida Magalhães, uma rodovia construída na região da borda metropolitana do Rio de Janeiro, com o propósito de diminuir o tráfego intenso da população que circula pela cidade e o escoamento logístico de mercadorias. 
9. Informação retirada de reportagem do jornal o Dia. Link para acesso: https://odia.ig.com.br/ _conteudo/odiaestado/2014-09-08/seropedica-atrai-grandes-industrias-e-abre-vagas.html. Acessada em 30 de abril de 2019.

10. Eco-friendly é um termo utilizado em referência às atividades sem prejuízo do ecossistema local.

11. Informação disponível em: https://www.japanfs.org/en/news/archives/news_id031424.html. Acessada em 30 de abril de 2019.

12. Conceito japonês criado na década de 90 para nomear a reestruturação de cidades com planejamento urbano sustentável, como o projeto de Kitakyushu.

\section{RESUMOS}

A questão ambiental tem se tornado parte cada vez mais essencial das relações internacionais no mundo globalizado. Foi necessário estabelecer um consenso global para garantir a conservação e a proteção do meio ambiente e, consequentemente, da vida. Por outro lado, o modelo capitalista do sistema internacional se mostrou resistente à limitação do lucro em detrimento da preservação ambiental por si só. Dessa forma, os conceitos definidos nas discussões internacionais sobre o tema sofreram adaptações para tentar alcançar um equilíbrio entre as demandas econômicas e ecológicas do mundo. Este trabalho busca explicar a trajetória da formulação dos conceitos e práticas determinadas nas conferências ambientais internacionais e a aplicação desses conceitos dentro da lógica de acumulação do sistema capitalista atual. Como exemplo das práticas aplicadas sobre o conceito de desenvolvimento sustentável, é apresentada uma comparação entre os projetos sustentáveis de Seropédica (Rio de Janeiro, Brasil) e Kitakyushu (ilha de Kyushu, Japão).

Les questions environnementales sont devenues un élément de plus en plus essentiel des relations internationales dans le monde globalisé. Il était nécessaire d'établir un consensus mondial pour assurer la conservation et la protection de l'environnement et, par conséquent, de la vie. Par ailleurs, le modèle capitaliste du système international s'est montré résistant à la limitation des profits au détriment de la préservation de l'environnement. Ainsi, les concepts définis dans les discussions internationales sur le sujet ont été adaptés pour tenter d'équilibrer les exigences économiques et écologiques du monde. Cet article cherche à expliquer la trajectoire de la formulation des concepts et des pratiques déterminés lors de conférences internationales sur l'environnement et comment ces concepts sont actuellement appliqués dans la logique de l'accumulation du système capitaliste. À titre d'exemple des pratiques appliquées sur le concept de développement durable, une comparaison est présentée entre les projets de développement durable de Seropédica (Rio de Janeiro, Brésil) et de Kitakyushu (île de Kyushu, Japon).

La cuestión ambiental se ha vuelto cada vez más esencial de las relaciones internacionales en el mundo globalizado. Fue necesario establecer un consenso global para garantizar la conservación y la protección del medio ambiente y, consecuentemente, de la vida. Por otro lado, el modelo capitalista del sistema internacional se mostró resistente a la limitación del lucro en detrimento de la preservación ambiental por sí solo. De esta forma, los conceptos definidos en las discusiones internacionales sobre el tema sufrieron adaptaciones para intentar alcanzar un equilibrio entre las demandas económicas y ecológicas del mundo. Este trabajo busca explicar la trayectoria de la 
formulación de conceptos y prácticas determinados en las conferencias ambientales internacionales y cómo se da actualmente la aplicación de esos conceptos dentro de la lógica de acumulación del sistema capitalista. Como ejemplo de las prácticas aplicadas sobre el concepto de desarrollo sostenible, se presenta una comparación entre los proyectos sostenibles de Seropédica (Río de Janeiro, Brasil) y Kitakyushu (isla de Kyushu, Japón).

The environmental issue has become an increasingly essential part of international relations in the globalized world. It was necessary to establish a global consensus to guarantee the conservation and protection of the environment and, consequently, of life. On the other hand, the capitalist model of the international system proved resistant to the limitation of profit to the detriment of environmental preservation alone. Thus, the concepts defined in the international discussions on the subject have been adapted to try to reach a balance between the economic and ecological demands of the world. This work seeks to explain the trajectory of the formulation of concepts and practices determined in the international environmental conferences the application of these concepts within the logic of accumulation of the current capitalist system. As an example of the applied practices on the concept of sustainable development, a comparison between the sustainable projects of Seropédica (Rio de Janeiro, Brazil) and Kitakyushu (Kyushu Island, Japan) is presented.

\section{ÍNDICE}

Mots-clés: environnement; développement durable; conférences internationales; relations internationales; restructuration territoriale-productive.

Keywords: environment; sustainable development; international conferences; international relations; territorial-productive restructuring.

Palabras claves: medio ambiente; desarrollo sostenible; conferencias internacionales; relaciones internacionales; reestructuración territorial-productiva.

Palavras-chave: meio ambiente; desenvolvimento sustentável; conferências internacionais; relações internacionais; reestruturação territorial-produtiva.

\section{AUTOR}

\section{LETÍCIA MELLO DE MENDONÇA}

Graduanda em Relações Internacionais pela Universidade Federal Rural do Rio de Janeiro

E-mail: leticiia_mello@hotmail.com 